\title{
O CORPO COMO IMAGEM, A IMAGEM COMO CORPO
}

\section{Academicismo e Modernismo na América Latina. [1 ${ }^{\text {] }}$}

\begin{abstract}
Rosângela Cherem[2]
Participantes do Grupo de Pesquisa ( AL): Ana Lúcia Gil, Kamilla Nunes,

Letícia Weiduschadt e Rachel Reis de Araújo $3^{\text {[ }}$

Participantes do Grupo de Pesquisa (SC): Marina Rieck Borck,Giorgio Vicenzo Filomeno ${ }^{4}$
\end{abstract}

Resumo: Em 1885 Juan Manuel Blanes executou um óleo sobre tela medindo 106 por $156 \mathrm{~cm}$ e intitulado Demônio, mundo e carne, obra que apresenta um conjunto de elementos relevantes para pensar a produção pictórica latino-americana no último quartel do século XIX. Mesmo cumprindo expectativas de um circuito e atendendo a encomendas, alguns artistas conseguiram ultrapassar o caráter ilustrativo e/ou narrativo, guardando nos desnudos femininos todo um universo de inquietações e investigações plásticas que ultrapassavam tanto os limites de território e nação, como também de cópia e original, tanto remetendo a uma tradição visual, cujas remotas vibrações ainda lhes afetavam, como lançando prefigurações advogadas pelos modernistas que lhes sucederam.

Palavras-chaves: Juan Manuel Blanes; História da arte; imagem; sensibilidades e percepções; pintura.

PONTO UM. Juan Manuel Blanes nasceu em Montevidéo em junho de 1830, um mês antes do Uruguai proclamar sua independência. Desde os vinte anos afirmou-se como pintor, notadamente de cenas históricas e costumbristas, através das quais legitimava os eventos e personagens nacionais numa abordagem minuciosa e rigor documental que o consagraram e reafirmaram a consistência de seu desenho e sua habilidade de manusear as cores, procedimentos que também incidem em seus retratos produzidos em tonalidades cálidas. Tendo desfrutado de uma bolsa do Estado recém nascido para estudar em Florença e Roma entre 1860 e 1864, conquistou a

\footnotetext{
${ }^{[1]}$ Projeto Academicismo e Modernismo na América Latina.

${ }^{[2]}$ Rosângela Miranda Cherem. Professora do Departamento de Artes Plásticas do Centro de Artes, UDESC.

${ }^{[}{ }^{]}$Acadêmicas participantes do Projeto Academicismo e Modernismo na América Latina, do mesmo grupo de pesquisa das orientadoras Rosângela Miranda Cherem (coordenadora do projeto AL) e Sandra Makowiecky (Coordenadora do projeto SC), além de Kamilla Nunes bolsista PROBIC, acadêmica do curso de Licenciatura em Artes Plásticas; Letícia Weiduschadt, bolsista PROBIC, acadêmica do curso de Licenciatura em Artes Plásticas; Ana Lúcia Gil, bolsista PROBIC, acadêmica do curso de Licenciatura em Artes Plásticas e Rachel Reis de Araújo, bolsista voluntária, acadêmica do curso de Licenciatura em Artes Plásticas.

${ }^{4}\left[4^{]}\right.$Acadêmicos do Curso de Bacharelado em Artes Plásticas - Ceart/UDESC, bolsistas PROBIC, UDESC, participantes da pesquisa Academicismo e Modernismo em Santa Catarina
} 
maturidade e credibilidade artística na mesma época em que seu país construía um repertório imagético povoado de personagens e enredos necessários tanto a sua definição como território, quanto uma nação com identidade própria.

Todavia, desviando desta trajetória em 1885, quando já voltara a residir na Itália, o artista produziu um quadro de elevado poder alegórico, embora nada explicitamente apegado às narrativas mitológicas, bíblicas ou literárias e nem portador de um caráter moral, político, religioso ou histórico. Trata-se de Demônio, mundo e carne, obra enviada para a Exposição Internacional de Paris em 1900 e que parecia caminhar na contra-mão das experimentações pictóricas que germinavam no ventre das vanguardas. Porém, mais do que exigir entendimento de um espectador iniciado nos gêneros pictóricos e conhecedor das prescrições acadêmicas, o que parece se configurar aqui é uma discussão sobre a natureza da pintura e o poder da imagem ${ }^{5}$.

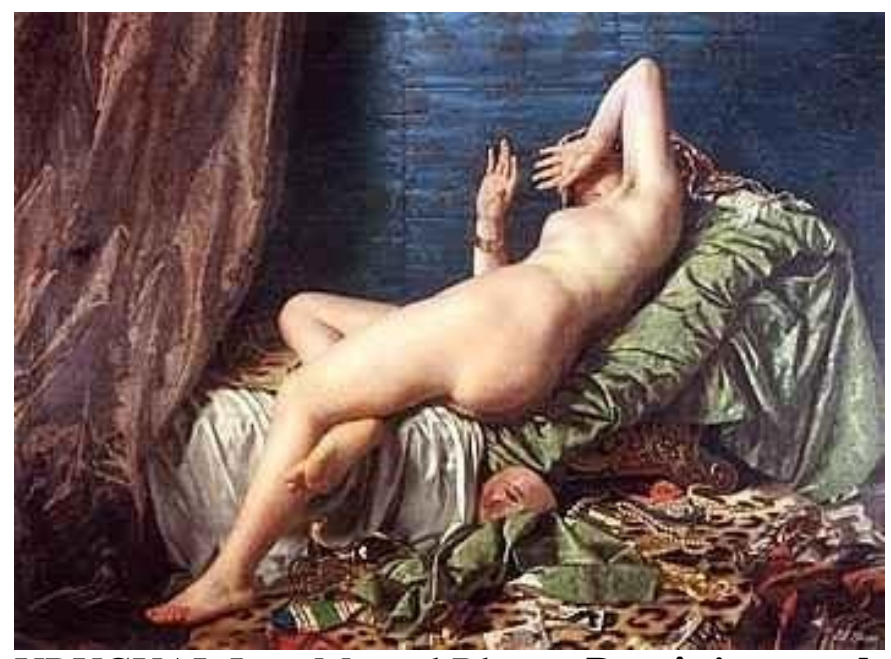

URUGUAI. Juan Manuel Blanes. Demônio, mundo e carne.

1885 - Óleo s/ tela. 1,06 x 1,56 cm. Coleção Museu Municipal Juan Manuel Blanes. http://www.montevideo.gub.uy/museoblanes/blanes.htm

Em destaque, a maciez de um corpo nu deitado sobre divã, estendido em posição oblíqua mas com as pernas cruzadas e com uma delas para fora do leito. Não está em posição confortável e parece ter sido surpreendido por uma intensa claridade que faz com que a mulher conduza as mãos em direção ao rosto, ocultando-o na tentativa de proteger os olhos. Ocorre que a fonte de tal claridade, possivelmente uma janela, não se encontra na tela mas provém do mesmo lugar em que se situa o espectador. Os gestos femininos parecem suspensos num instante de perturbação, fazendo

\footnotetext{
${ }^{5}$ Informações obtidas a partir dos seguintes sites: www.rau.edu.uy/uruguay/cultura/blanes $2 . \mathrm{htm}$ www.artemercosur.org.uy/museos/uruguay/blan.html www.mnav.gub.uy/blanes.htm
} 
com que o possível retrato se torne uma cena de privacidade invadida mas mal sucedida, na medida em que a identidade permanece irreconhecível e as partes mais eróticas ocultas. O ambiente é de desalinho, mas as texturas suaves: seda, cetim, veludo. Uma enigmática beleza permanece, sendo que apenas o desejo, alimentado pela imaginação, poderá deslindá-la.

Reconhecida a oferenda pictórica, impossível deixar de olhar. Contudo, a armadilha é fatal, uma vez que há um mistério impossível de decifrar naquela realidade produzida pelo manejo astucioso do pincel e uso da tinta, duplicado pelo título da obra. É quando o delírio da pintura se realiza, fazendo com que o olhar que almeja tocar seja o mesmo que se torna atingido pela realidade imagética. Assim, observador e observado apenas se espiam. No cruzamento de afecções, acontece uma tensão produzida pelo movimento de invasão de olhares que se lançam e se previnem em relação ao outro, pois enquanto o espectador penetra e percorre a tela, a jovem se protege da luz e se oculta do olhar alheio, embora tente através da fresta de seus dedos reconhecer o intruso. Ao se dar conta deste jogo é no espectador que se replica a sensação de ser vulnerável e devassado e se rebate a possibilidade de ver-se como apenas uma estranha mancha localizada do outro lado da tela.

PONTO DOIS. Aparentemente, diante da natureza dos procedimentos pictóricos em tempos de inquietações impressionistas e estéticas sucedâneas, o artista teria privilegiado as questões técnicas sobre as temáticas e, reconhecendo um meio onde a produção industrial e a reprodutibilidade técnica se acentuavam, reivindicava uma poética que não descuidasse da fatura. Todavia, observando atentamente, é possível avistar um cruzamento através do qual procurava manter vínculo com a tradição acadêmica e, ao mesmo tempo, assimilar as interrogações de um realismo ótico sofisticado à maneira de Courbet e Manet. Borrando os limites daquilo que se convencionou rotular de moderno e pré-moderno ou tradicional, voltado para um questionamento acerca da imagem e dos problemas da realidade plástica, tal repertório resultava numa sorte de meta-pintura, ou seja uma abordagem pensante da pintura, onde o assunto era definido nela mesma pelo jogo de composição e desenho, cores e luzes, texturas e formas. 


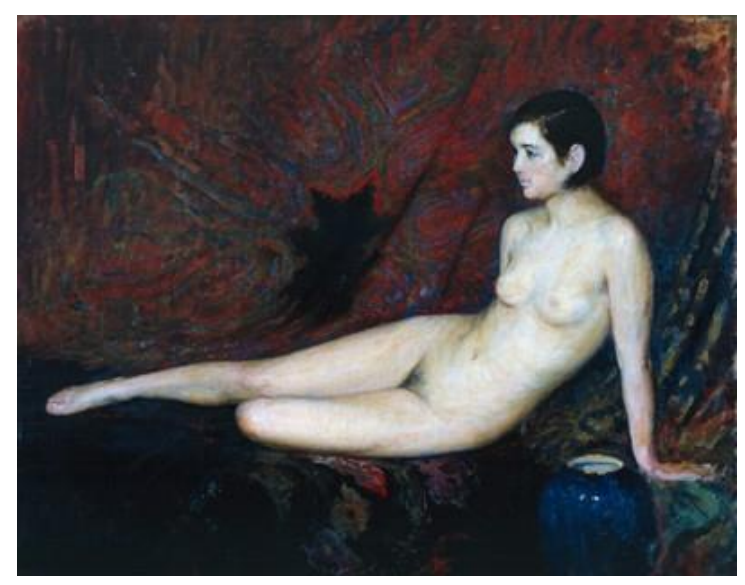

ARGENTINA, Ernesto de la Cárcoba. Sorpresa. 1896

http://static.pagina12.com.ar/fotos/espectaculos/20070717/notas_e/na29fo02.jpg

Bem verdade que outros artistas do período e mesmo depois, mantendo sensibilidades e percepções semelhantes, incursionaram pela mesma temática e experimentações vizinhas, multiplicando exemplos como o fizeram no Peru Luis Montero com Vênus adormecida (1851, óleo s/ tela, 82 x $123 \mathrm{~cm}$ ); na Argentina Eduardo Sívori com $O$ despertar da criada (1867, óleo s/ tela, 192 x $131 \mathrm{~cm}$ ); no México Felipe Gutiérrez com A caçadora dos Andes (1891, óleo s/ tela, 100 x 162 cm); no Peru Daniel Hernandez com Nu Reclinado (1899, óleo s/ tela, 93,3 x 151,1 cm). Tal parece ter sido também o caso de $\mathrm{Nu}$ com ventarola (1884), óleo sobre tela medindo 150 por 200 $\mathrm{cm}$, executado enquanto Rodolfo Amoedo era bolsista na capital francesa. Nesta obra, sob a enigmática beleza de um corpo com rosto ausente, o artista materializou seu poder figural de fazer emergir pela matização das cores e sobreposição de texturas uma sensualidade carnal em pele e pelos.

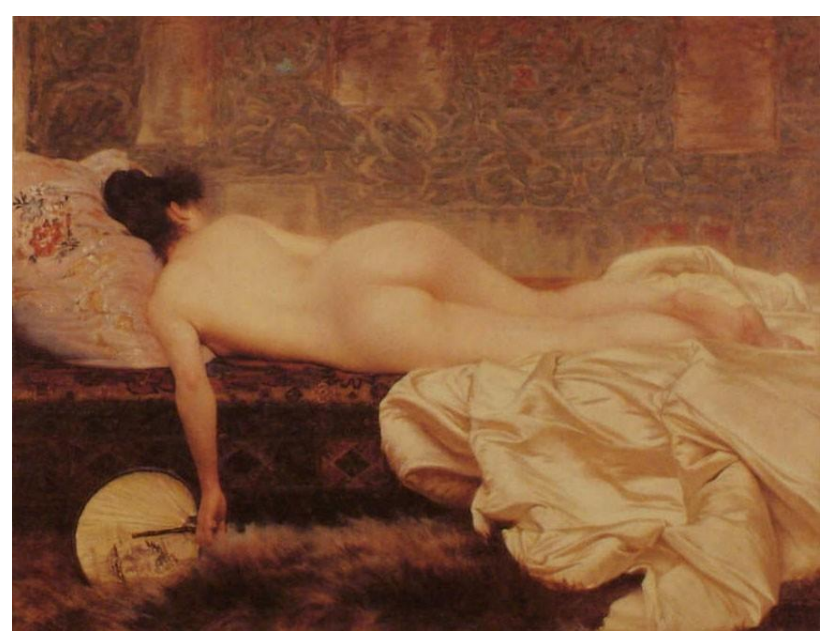

BRASIL. Rodolfo Amoedo. Estudo de mulher. 1884.

óleo sobre tela, 150 x $200 \mathrm{~cm}$. Museu Nacional de Belas Artes do Rio de Janeiro. http://www.dezenovevinte.net/bios/bio_ra_arquivos/ra_1884_estudo.jpg 
Mesmo depois da primeira guerra mundial e aquilo que se convencionou chamar de vigências vanguardistas, as experimentações pictóricas através de corpos femininos, deitados ou reclinados e quase sempre sem roupas, prosseguiram, sendo este o caso na Argentina com Emílio Centurion em A Vênus crioula (1934, óleo s/ tela, 183 x 130 cm); na Colômbia com Ignacio Gómez Jaramillo em A dama Vestida de Blanco (1937, óleo sobre tela, 64,5 x $80 \mathrm{~cm}$ ); no Brasil, Eliseu Visconti com Mãe e filho (1940, óleo sobre tela, 46 x 65 cm); na Colômbia Eugenio Zerda com Nu (1945, óleo s/ tela, 70x107 cm) e Miguel Díaz Vargas com Estudo em Cinzas (1944, óleo s/ tela, 110x90 cm). Vulneráveis em seu estado absorto, frágeis em seu sossego instável, entregues à languidão, incônscios ou perturbados pelo olhar alheio, os corpos nascem ora como pretexto para as fantasias dos espectadores ${ }^{6}$, ora como objeto das mais diversas experimentações plásticas, tornandose ora corpo que tenta escapar através de um ponto de fuga, insinuando um tempo-espaço que se abre e se fecha sobre aquilo que ali se apresenta, ora jogo de fragmento e forma, mancha e cor viva, que nada pretende aludir para além ou atrás de $\mathbf{s i}^{7}$.

PONTO TRÊS. Compondo e recompondo seu próprio arsenal pictórico, é importante assinalar que certos artistas realizaram este movimento a partir da imagem do corpo feminino deitado ou reclinado que reverberava desde as esculturas deitadas nos túmulos ou nos divãs conforme as cerâmicas antigas, relevos funerários e afrescos pompeianos, passando pela infindável série moderna, onde aquelas formas corpóreas retornam desde nas telas de Ticciano, Velásquez e Goya ou, posteriormente, nas de Diego de Rivera e Cândido Portinari. Se no fim dos oitocentos Nietzsche iria vaticinar a morte de Deus para falar do fim das certezas e dos grandes sistemas explicativos, desde algumas décadas antes Courbet e Baudelaire tentavam encarar os problemas da carne e do corpo feminino em relação direta com a anti-beleza. O corpo coagulado como matéria artística, literária ou pictórica, emblematizava a carne do mundo e a superfície das coisas, sendo que tanto na Europa como na América Latina tais injunções comparecem, quer no chamado ambiente acadêmico como naquilo que o interrogou e buscou suceder.

\footnotetext{
${ }^{6}$ OLIVEIRA, Maria Alice Milliet (org). O desejo na Academia, 1847 -1916. Catálogo de Exposição. PINACOTECA-SP, PW, 1991

${ }^{7}$ GRUPO VELOX ( Org.).Pintura latinoamericana. Buenos Aires: Ed. El Ateneo, 1999.
} 


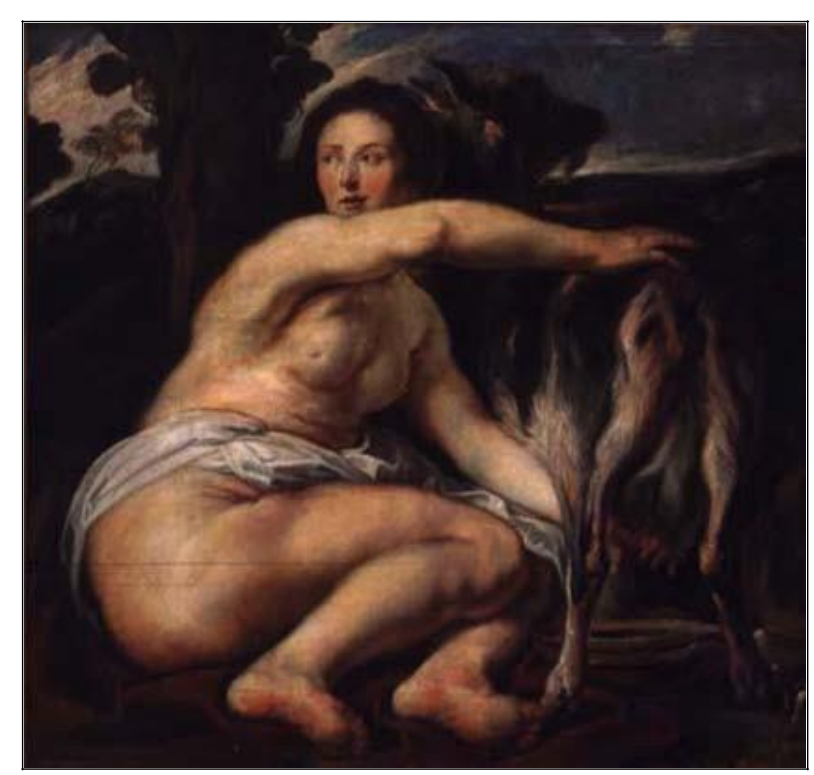

CHILE. Marco Aurélio Bontá Costa. Infancia De Júpiter.

Museo de Arte Contemporáneo, Universidad de Chile, Santiago

http://www.mac.uchile.cl/virtual/galerias/desnudo2.html

Para alcançar as pulsações contidas em obras como Demônio, mundo e carne talvez seja preciso ultrapassar as questões de território e nação para reconhecer que, por vezes mesmo cumprindo certas expectativas e atendendo às encomendas, os artistas conseguiram se distanciar do caráter ilustrativo e/ou narrativo, guardando naquelas formas todo um universo de inquietações e investigações plásticas que vinham sendo delineados desde o alvorecer moderno. Problemática que, por sua vez, adquire maior relevância em relação aos valores esboçados especialmente num tempo em que os sistemas explicativos iam sendo substituídos por sentimentos de extravio e errância, visibilizados na arte pela noção de bellum em contraposição ao belo e de desastre em substituição à aura das grandes certezas e crenças. Desse modo, se já parece lugar-comum dizer que estamos imersos no excesso de imagens a que somos bombardeados diariamente, torna-se pertinente à História da Arte considerar um campo em que os diferentes modos de produção e circulação imagética possam ser problematizados. 


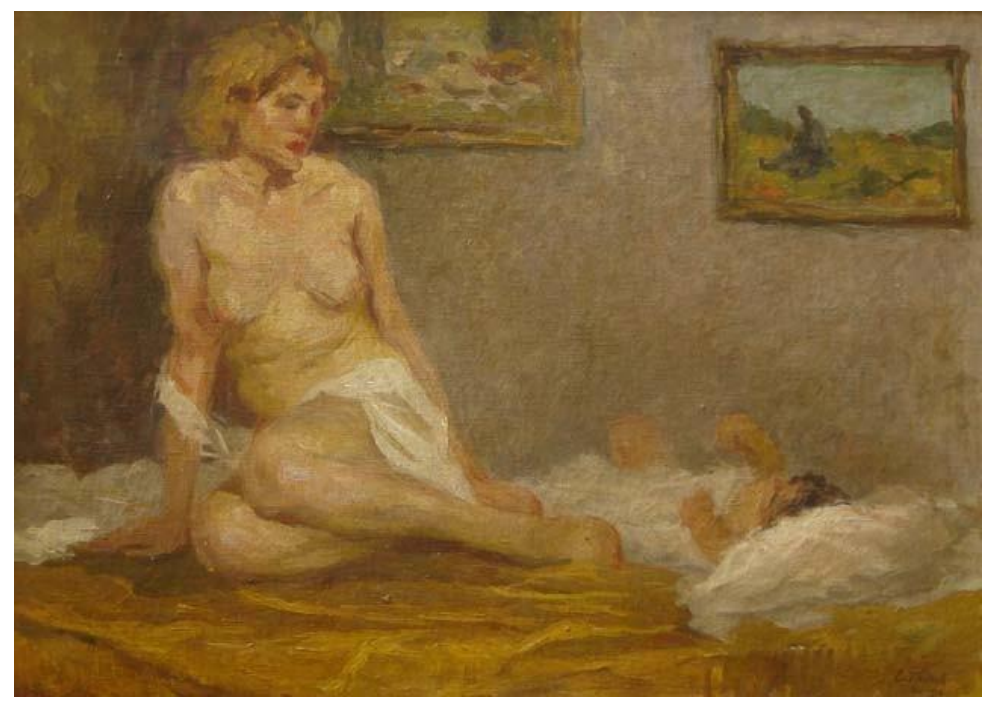

BRASIL. Eliseu Visconti. Mãe e filho. 1940

Óleo sobre tela - 46 x $65 \mathrm{~cm}$

\section{http://www.arteeeventos.com.br/paginas_leilao/categoria.asp?iCat=353\&offset=102}

Alguns estudos têm procurado evidenciar que os recortes definidos para um modernismo depois da primeira grande guerra em vários países latino americanos podem ser lidos como uma construção discursiva, em grande parte associada à memória de seus protagonistas, interessados em se contrapor às academias de belas artes como meio para se afirmar numa situação de ruptura com a tradição ${ }^{8}$. Porém, tudo indica que se as chamadas vanguardas latino-americanas adotaram freqüentemente bandeiras anti-acadêmicas como parte de seu desejo de aggiornamento é porque ignoravam ou esqueciam os choques produzidos intencionalmente por participantes de salões oficiais europeus, tal como no caso de Manet. Em outras palavras, mesmo dentro de certos circuitos oficiais as posturas inquietas e chocantes, disfarçadas ou não, já se deixavam ver bem antes daquilo que se delimitou como próprio ao século XX. Tal pressuposto, longe de pretender um ponto originário e primordial, parece conveniente para que se possa tanto reconhecer os esforços de ultrapassagem e ruptura estética no seio dos meios onde aparentemente apenas proliferavam convenções, como para abordar certas obras artísticas mais pela concomitância de certas contingências do que como simples ecos europeus.

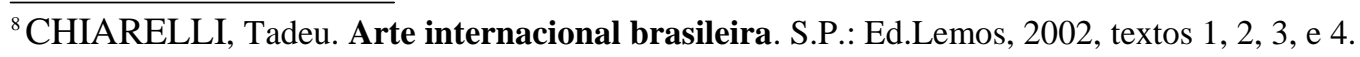




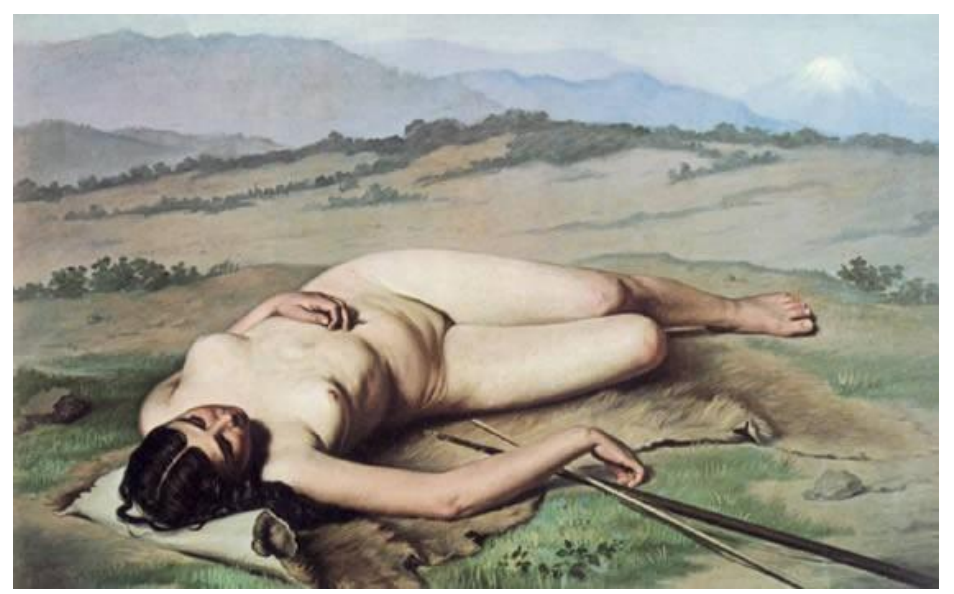

MEXICO. Felipe Gutiérrez. A caçadora dos Andes. 1891

Óleo s/ tela, 100 x $162 \mathrm{~cm}$ Museu Nacional de Arte, Cidade do México

http://redescolar.ilce.edu.mx/redescolar/proyectos/acercarte/arte_mexicano/artemex $5 /$ mexexp05a3.htm

Embora a titulação da obra só possa ser problematizada como correspondência e não como equivalência, uma vez que dizer não é ver e entre ambas as instâncias o que se coloque é um abismo, convém prestar atenção ao gesto através do qual, por vezes o artista considera a legenda como uma espécie de seta, sinalizando para o conteúdo pictórico como uma consistência que desfaz o mundo ótico e propõe um jogo de tensões dinâmicas, variações lógicas e modulações coloridas que se recusa a ser ilustração de um corpo reapresentado ao mesmo tempo em que se produz o colorido da carne pictórica. Estendidos na paisagem natural ou espalhados nos labirintos do leito, onde a maciez de sua pele tanto acolhe o olhar que a atravessa como contrasta com sua intimidade avassalada, aqueles corpos não apenas se colocam na relação proximidade-distância com o mundo alhures à tela, como também interrogam aquele mundo, retornando para a propriedade da pintura de fazer ser aquilo que ela não é, permitindo que aquele que se situa diante dela possa percorrê-la através de uma espécie de percurso tátil do olhar.

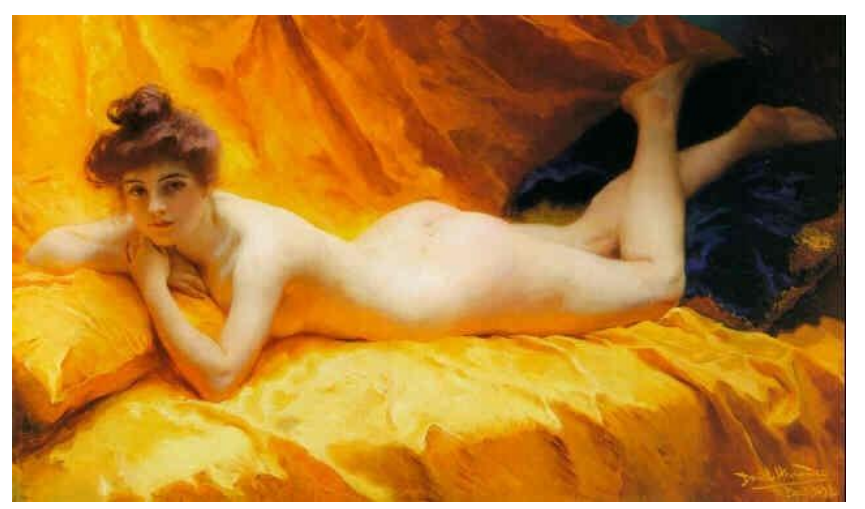

PERU. Daniel Hernandez. Nu Reclinado. 1899.

Óleo s/ tela, 93,3 x 151,1 cm. 
http://www.artnet.com/artist/8159/daniel-hernandez.html

Conforme tal entendimento, trata-se de bascular menos pelos manuais de estilo e escolas e mais através da constituição de certas combinações e particularidades, onde a obra de arte pode ser lida em novas complexidades e articulações, particularmente pelo seu caráter de recorrência e sobrevivência. É quando a noção de sintoma se afirma como sendo aquilo que interroga a imagem em sua relação com o tempo, interrompendo o fluxo regular das coisas e tornando-se uma espécie de lei avariada e subterrânea que persiste como retorno de uma enfermidade. Nem conceito semiológico, nem conceito clínico, trata-se de uma noção operatória que recusa submissão ao tempo eucrônico, destacando-se como aparição de uma latência que conjuga diferença e repetição, proximidade e distância, interior e exterior, imobilidade e aceleração 9 .

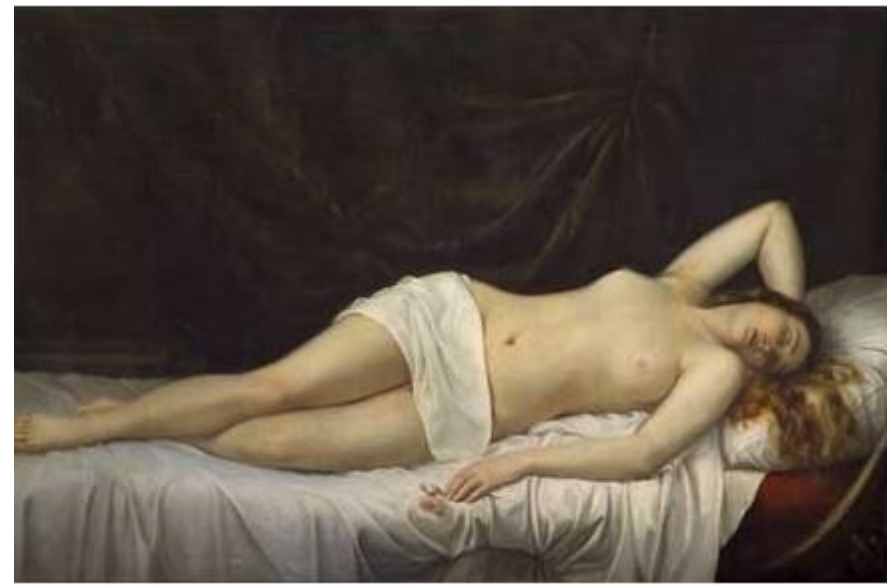

PERU. Luis Montero. Venus adormecida. 1851,

óleo s/ tela, 82 x $123 \mathrm{~cm}$, Museu Nacional de Arqueologia, Antropologia e História http://www.limaeasy.com/museums/museodearte.html

PONTO QUATRO. Para prosseguir na abordagem da recorrência pictórica dos corpos femininos deitados e desnudos, como considerar as implicações do critério cópia-original? A este respeito talvez seja conveniente lembrar que em temporalidade muito próxima a que Blanes pintou Demônio, mundo e carne, Rodin concebia suas esculturas pelo desenho e materializava-as pelas escaiolas, mas delegava aos fundidores e patinadores a tarefa de acompanhar os vazados e seus acabamentos. Por sua vez, este procedimento indica um modo de conceber o gesto artístico indiferente à reduplicação da obra, reconhecendo sua continuidade como forma e contra-forma, através da cadeia incessante que se afirma numa série, tal como a fotografia se reproduz infinitamente como cópia sem original. Assim, em tempos de reprodutibilidade técnica, embora

${ }^{9}$ DIDI-HUBERMAN, Georges. Ante el tiempo. Buenos Aires: Adriana Hidalgo, 2006, cap 
antes do advento dos readymades, aquele binômio caro ao romantismo já revelava sua fragilidade como princípio artístico ${ }^{10}$.

Para considerar a sobrevivência das imagens como reduplicação sem original também é preciso abandonar a idéia de que a Europa coube o lugar principal de palco criador e fora de suas fronteiras o lugar da mera assimilação de influências, como se o antigo continente e seus centros de referência artística fossem uma espécie de sementeira primordial, ignorando o constante movimento de renitência e reelaboração da imagem artística, bem como de concomitância e ressonância das poéticas e das faturas em relação à produção plástica. Implícita nesta compreensão permaneceria a noção das fímbrias acanhadas da colônia-província em relação à metrópole-Europa/Estados Unidos.

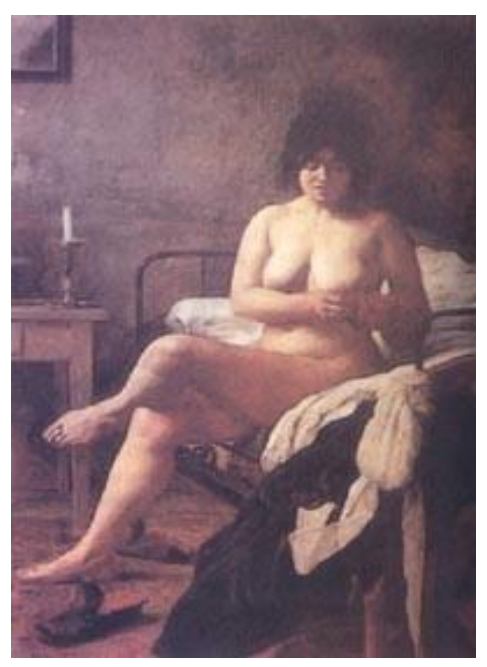

ARGENTINA. Eduardo Sívori . EI despertar de la criada.1867

Óleo s/ tela, 1,92 x 1.31m, Museu Nacional de Belas Artes

http://biografias0.iespana.es/biografias0/generacion_del_80.htm

Por sua vez, distinguido os sentidos aparentemente comuns entre repetição e generalidade, Deleuze $^{11}$ assinala que a repetição não possui um caráter homogeneizador, mas traz em seu movimento uma diferença que se constitui como lapso e desvio em relação ao padrão. Assim, não está relacionada ao ordenamento do idêntico, mas à noção nietzscheneana de retorno, ou seja, enquanto a generalidade obedece a leis com permanências e variáveis, possibilitando que um termo possa ser traduzido por outro e o particular possa ser reposto e substituído, a repetição se coloca como vibração secreta, operando como dom e pelo roubo, desvio ou transgressão de uma potência singular que ocorre entre generalidades.

\footnotetext{
${ }^{10}$ KRAUSS. Rosalind La originalidad de la vanguardia Y otros mitos modernos. Madrid: Alianza, 1996.

${ }^{11}$ DELEUZE, Gilles. Diferença e Repetição. S.P.: Ed. Graal, 1988, p. 21 e seg.
} 


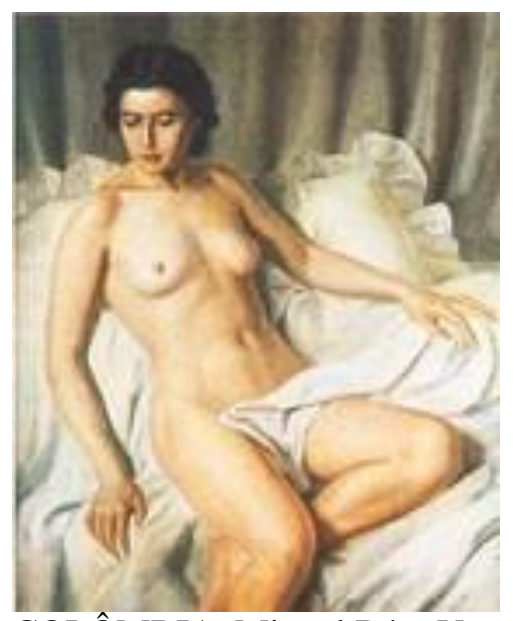

COLÔMBIA, Miguel Díaz Vargas. Estudo em Cinzas. 1944.

Óleo s/ tela, 110x90 cm.

Museu Nacional da Colômbia

http://www.indetectable.org/pages/noticias/calidadarv.htm

Sendo a arte o lugar onde as diferentes repetições coexistem, a repetição é diferença sem conceito, não porque se constitui como reprodução do mesmo e sim porque é arremesso em direção ao outro. Eis os contornos de um campo, onde as obras podem ser consideradas na relação com as séries e sua abordagem pode incidir sobre os vestígios da repetição como diferença, cujas injunções tanto acolhem a ação do tempo sobre as coisas, como as contingências, os acidentes e seus efeitos. Eis também como academicismo e modernismo se desfazem como rótulos, enquanto preservam elos com uma distante história da experiência visual e alimentam o entendimento de que toda a criação possui seu duplo não na originalidade nascida de um ponto zero ou a partir de uma ultrapassagem, mas sim no reaparecimento de remotos problemas que se refazem incessantemente para voltar como lapso e esquecimento.

PONTO CINCO. Considerando o retorno do distante, é pertinente assinalar que, particularmente desde o advento dos museus e da imprensa, bem como da fotografia e da publicidade, do cinema e dos vídeos, as imagens artísticas sofreram profundas metamorfoses em relação aos seus sentidos e concepções mais remotas. Porém, se o museu foi um dia o local onde as obras puderam sobreviver, apesar de terem sido deslocadas do lugar para o qual foram concebidas, um novo arsenal imagético alimentado pela ampliação da reprodutibilidade técnica, privado e desierarquizado permitiria que as obras se reduplicassem infinitamente, disseminando-se num mundo aparentemente possível a todos. Assim, não se trata da recordação de um lugar mas a criação de um lugar imaginário ${ }^{12}$.

\footnotetext{
${ }^{12}$ MALRAUX, André. O museu imaginário. Lisboa/ São Paulo: Ed. 70, 2000, cap.IV.
} 
Tal fenômeno mudaria o eixo das interrogações sobre as obras, interessando menos o sentido que um dia tiveram e mais as inquietações e cintilações que ainda são capazes de produzir, dado que o museu imaginário com sua força de álbum e em seu poder de ressuscitar, iluminar e apagar obras, bem como de alimentar a imaginação, define o modo como as obras de arte podem ser conhecidas. Por sua vez, aquela mesma metamorfose também alteraria a noção de arquivo, ultrapassando tanto sua condição de reservatório dos eventos singulares ou arsenal legitimador e depositário da memória dos nomes próprios, como também remetendo a uma alteridade infinita, ampliando o fato de que os conceitos, como as imagens, jamais se encontram consigo mesmo, vivendo apenas como verdade espectral ${ }^{13}$.

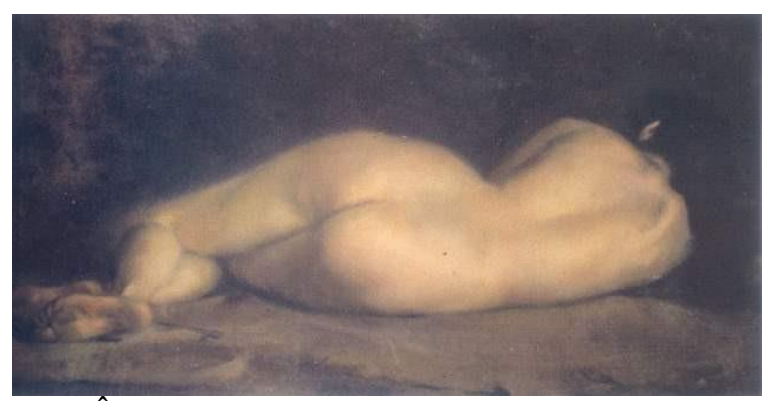

COLÔMBIA. Eugenio Zerda .Nu. 1945.

Óleo s/ tela, 70x107 cm. Museu Nacional da Colômbia. http://www.indetectable.org/pages/noticias/in24.pdf

Colocados sob suspeita, os registros e fontes ali guardados, cuja sobrevida está em parte assegurada pela mutação dos sentidos, passariam a ser considerados como uma rede secreta que, escondendo o arbitrário e o tateante, ordena as coisas e os fenômenos, naturaliza as semelhanças ou diferenças e produz aproximações, permitindo estranhar e suspeitar das classificações que produzem vertiginosos encontros, dispõem e regulam coisas díspares e fazem com que as mesmas possam ser reconhecidas e apaziguadas como familiares.

PONTO SEIS. É de Didi-Huberman a reflexão de que a pintura pensa e talvez essa seja uma questão infernal para o pensamento ${ }^{14}$. Por sua vez, a concepção que aí se apresenta permite tanto pensar a imagem pelo recurso do anacronismo, em conformidade com as reflexões de Warburg e Benjamin acerca das impurezas temporais, como também se aproxima da temática das ruínas circulares e dos labirintos borgeanos. Situando as experiências humanas para além dos meros enquadramentos e continuidades cronológicos, as imagens como os acontecimentos passam a ser concebidos como sonhos renitentes ou questões irresolutas que retornam sob certas injunções e contingências, persistindo e insistindo como ondas mnemônicas. Fluxo e refluxo, beleza e caos, criação e destruição, pintura do mundo e assassinato da coisa, mundo da pintura e simbolização da

\footnotetext{
${ }^{13}$ DERRIDA, Jacques. Mal de arquivo.R.J.: Relume Dumará,2001, pág.109 e seg.

${ }^{14}$ DIDI-HUBERMAN, Georges. La peinture incarnee. Paris: Les Éditions de Minuit, 1995.
} 
ausência, eis o movimento pendular que percorre das convenções mais realistas às experimentações mais ousadas.

Questão que, ao mesmo tempo, funda e solapa o fenômeno do olhar, emoldurando ou preenchendo o vazio da cena, Demônio, mundo e carne parece dirigir-se intimamente aquele que para ela se volta, ao mesmo tempo em que remete ao exterior ou fundo indefinido pelo qual o rosto se afirma em seu desaparecimento e uma forma pode ser reconhecida enquanto os traços de sua individualidade desaparecem. Sendo a eficácia da imagem alcançada no jogo de texturas e rasgos, oferenda e revelação, o olho transforma as coisas enquanto também é transformado por elas. Problematizando uma relação entre a pintura do corpo e o corpo da tela, Blanes assinala seu poder de transformar as particularidades da superfície na própria latência da carne, atribuindo às manchas pigmentares e seus efeitos colorantes, às coberturas e camadas uma potência capaz de alterar, confundir e perturbar a matéria, produzindo um trânsito figural onde as qualidades óticas se tornam qualidades táteis, artifício em que obscuridade de um procedimento se torna, ao mesmo tempo, ilusão e evidência realista.

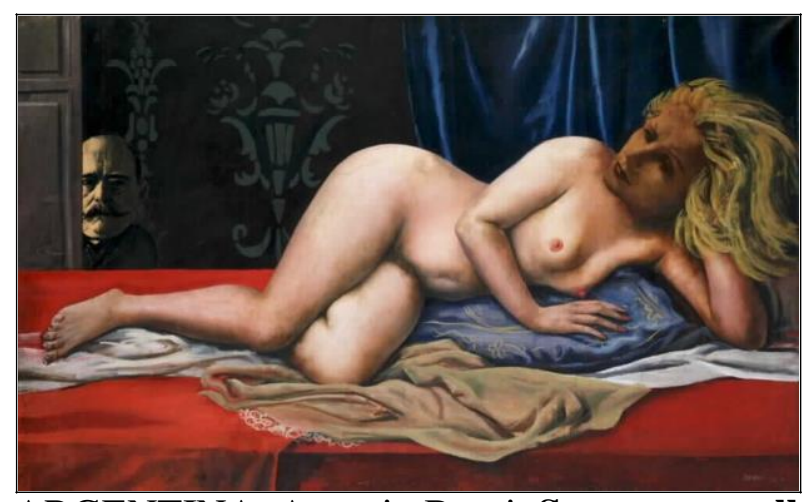

ARGENTINA. Antonio Berni. Susana e o velho. 1931

http://www.oni.escuelas.edu.ar/olimpi98/juanitoyramona/laetapa.htm

Sendo a desnudez matéria de trabalho artístico e como tal uma forma específica do nu, constituindo-se como vestimenta de uma outra coisa, tal como do erotismo, da verdade, da vergonha, em que a superfície pictórica encena sentidos da carnalidade e de seu revestimento epitelial, para alcançar o corpo é preciso que o olhar produza um rasgo ${ }^{15}$. Considerando as questões plásticas que emergem na superfície mas ultrapassam tanto a noção de representação daquilo que pode ser narrado ou documentado como a condição ilustrativa da imagem, a pele pictórica do quadro de Amoedo vem atingir o olhar e produzir uma abertura, operando um deslizamento através do qual algo que se faz passar por uma densidade orgânica remete ao exterior. Assim, a pele pictórica como uma coisa que remete a outra e está fora, torna-se uma pele corpórea.

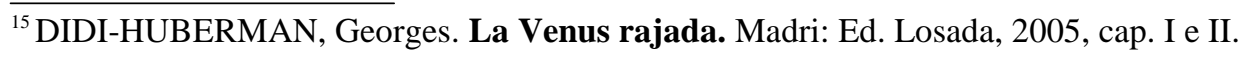


Desse modo, ocorre uma travessia e uma obliteração. Enquanto o olho que se alonga e se projeta produz uma espécie de espessura ou invólucro, algo escapa e jamais se revela, impedindo de alcançar as coisas em seu ser. Neste jogo de luz e opacidade, distância e proximidade, superfície e profundidade, aparição e ocultação advém uma cruel contradição nascida do cruzamento entre o visível e o tangível, através do qual o olhar só se realiza como atravessamento, cisão ou fenda, enquanto o visível permanece como superfície de uma profundidade maciça, repleta de trevas e segredos. Assim, naquilo a que se poderia chamar de magia da figurabilidade, destaca-se o poder imagético capaz de proporcionar um delírio de penetração visual e aderência onde comparecem fulguração e vestígio, sublimidade e burla, guardando uma relação fantasmática com aquele que a executa e o mundo ao qual pertence.

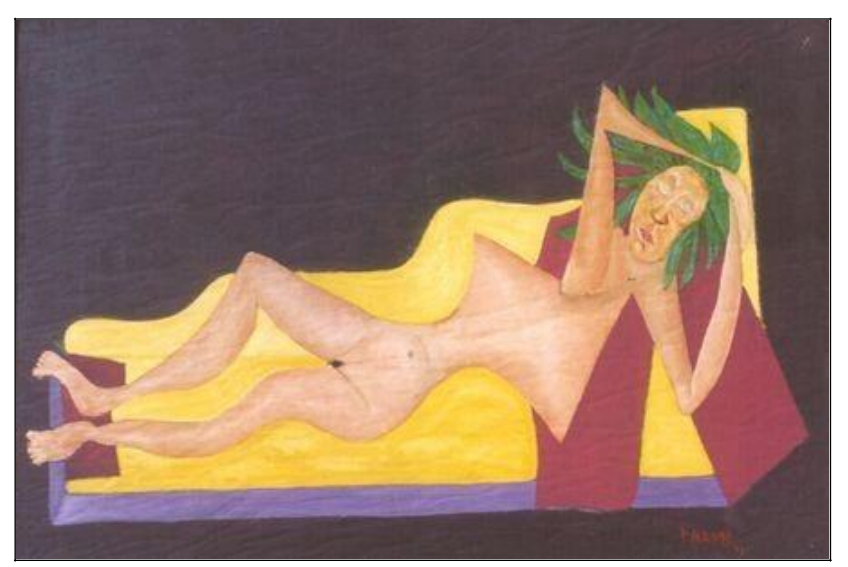

PARAGUAI. José Parodi. A televisão me aborrece. 2003. Técnica mista, 100 x $70 \mathrm{~cm}$. http://www.rosariarte.com.ar/p/parodi/001058.htm 